\title{
The glycan-binding protein galectin-1 controls survival of epithelial cells along the crypt-villus axis of small intestine
}

\author{
C Muglia ${ }^{1}$, N Mercer ${ }^{1}$, MA Toscano ${ }^{2}$, M Schattner ${ }^{3}$, R Pozner ${ }^{3,4}$, JP Cerliani ${ }^{2}$, R Papa Gobbi ${ }^{1}$, GA Rabinovich ${ }^{2,4,5}$ and GH Docena ${ }^{\star, 1,5}$
}

Intestinal epithelial cells serve as mechanical barriers and active components of the mucosal immune system. These cells migrate from the crypt to the tip of the villus, where different stimuli can differentially affect their survival. Here we investigated, using in vitro and in vivo strategies, the role of galectin-1 (Gal-1), an evolutionarily conserved glycan-binding protein, in modulating the survival of human and mouse enterocytes. Both Gal-1 and its specific glyco-receptors were broadly expressed in small bowel enterocytes. Exogenous Gal-1 reduced the viability of enterocytes through apoptotic mechanisms involving activation of both caspase and mitochondrial pathways. Consistent with these findings, apoptotic cells were mainly detected at the tip of the villi, following administration of Gal-1. Moreover, Gal-1-deficient ( Lgals $1^{-1-}$ ) mice showed longer villi compared with their wild-type counterparts in vivo. In an experimental model of starvation, fasted wild-type mice displayed reduced villi and lower intestinal weight compared with Lgals ${ }^{-/-}$mutant mice, an effect reflected by changes in the frequency of enterocyte apoptosis. Of note, human small bowel enterocytes were also prone to this pro-apoptotic effect. Thus, Gal-1 is broadly expressed in mucosal tissue and influences the viability of human and mouse enterocytes, an effect which might influence the migration of these cells from the crypt, the integrity of the villus and the epithelial barrier function.

Cell Death and Disease (2011) 2, e163; doi:10.1038/cddis.2011.44; published online 26 May 2011

Subject Category: Experimental Medicine

The intestinal mucosa is continuously challenged by a variety of antigens from the diet and from commensal or pathogenic microorganisms, which should be carefully discriminated in order to either mount an active immune response or to promote immune tolerance. ${ }^{1}$ Epithelial cells, which are critical in this regulatory pathway, differentiate from stem cells located in the crypts and undergo a highly regulated maturation program as they migrate along the crypt-villus axis, forming a dynamic renewing tissue that maintains the integrity of the intestinal epithelium. ${ }^{2}$ As enterocytes migrate upwards along the axis, they acquire a mature absorptive phenotype, and are finally eliminated by apoptosis at the top of the villus. Several signaling cascades control cellular proliferation, differentiation, migration and apoptosis of enterocytes. ${ }^{3}$ Furthermore, different metabolites (iron, vitamins, amino acids, carbohydrates and lipids) and relevant enzymes including acyl-CoA synthetase serve as regulatory mediators that contribute to enterocyte renewal in the human intestine. ${ }^{3}$ However, the cellular and molecular mechanisms underlying the regulation of apoptosis of senescent enterocytes and maintenance of mucosal homeostasis, are still poorly understood.

Galectin-1 (Gal-1), an evolutionarily conserved $\beta$-galactoside-binding protein, has key roles in a variety of physiologic and pathologic processes. ${ }^{4,5}$ These functions include suppression of $\mathrm{T}$-cell responses through selective induction of $\mathrm{T}_{\mathrm{H}} 1$ and $\mathrm{T}_{\mathrm{H}} 17$ cell apoptosis ${ }^{4,5}$ and activation of tolerogenic circuits on dendritic cells. ${ }^{6}$ These glycosylationdependent functions account for the capacity of this lectin to dampen inflammation in autoimmune, chronic and acute inflammatory disorders, ${ }^{4,7-9}$ and to favor immune escape of certain types of cancer. ${ }^{10,11}$

Gal-1 is expressed in different portions of the human and mouse gastrointestinal tract, ${ }^{12-14}$ and similar to other members of the galectin family, has been implicated in different intestinal disorders. ${ }^{7,14-17}$ Gal-1 expression is downregulated in a mouse model of 2,4,6-trinitrobenzene sulfonic acid (TNBS)-induced colits and its therapeutic administration contributes to inhibition of $\mathrm{T}_{\mathrm{H}} 1$ and pro-inflammatory cytokines (TNF, IL-1 $\beta, \mathrm{IL}-12$ and IFN- $\gamma$ ), and remission of the

\footnotetext{
'Laboratorio de Investigaciones del Sistema Inmune, Facultad de Ciencias Exactas, Universidad de La Plata, La Plata, Argentina; ${ }^{2}$ Laboratorio de Inmunopatología, Instituto de Biología y Medicina Experimental, Consejo Nacional de Investigaciones Científicas y Técnicas, Buenos Aires, Argentina; ${ }^{3}$ Instituto de Investigaciones Hematológicas, Academia Nacional de Medicina, Buenos Aires, Argentina and ${ }^{4}$ Departamento de Química Biológica, Facultad de Ciencias Exactas y Naturales, Universidad de Buenos Aires, Buenos Aires, Argentina

*Corresponding author: GH Docena, Laboratorio de Investigaciones del Sistema Inmune, Facultad de Ciencias Exactas, Universidad Nacional de La Plata, Calles 47 y 115 , C 1900 La Plata, Argentina. Tel: + 54221425 0497; Fax: + 54221422 6947; E-mail: guidoc@biol.unlp.edu.ar

${ }^{5}$ These authors shared senior authorship.

Keywords: galectin-1; small bowel; enterocytes; apoptosis; mucosa

Abbreviations: Gal-1, galectin-1; FBS, fetal bovine serum; HBSS, Hank's buffered saline solution; PCNA, proliferation cell nuclear antigen; DAB, 3,3'diaminobenzidine tetrahydrochloride; SNA, Sambucus nigra agglutinin; PNA, peanut agglutinin; LEL, Lycopersicon esculentum lectin; PHA, Phaseolus vulgaris agglutinin; ZVAD-FMK, benzyloxycarbonyl-Val-Ala-Asp (OMe) fluoromethylketone; TUNEL, terminal deoxynucleotidyl transferase dUTP nick end labeling; Ac-DEVDAFC, N-acetyl-Asp-Glu-Val-Asp-AFC 7-amino-4-trifluoromethyl coumarin; Ac-DEVD-CHO, N-acetyl-Asp-Glu-Val-Asp-CHO aldehyde

Received 07.1.11; revised 13.4.11; accepted 13.4.11; Edited by G Melino
} 
clinical and histopathologic signs of inflammatory bowel disease. ${ }^{7}$ On the other hand, overexpression of Gal-1 has been linked to the progression of human colon carcinomas. ${ }^{12,16}$

The present study was aimed at elucidating the role of Gal-1 in the intestinal epithelial cell compartment. We found that Gal-1 binds to human and mouse enterocytes where it signals apoptosis through a caspase-dependent mechanism, leading to depolarization of the mitochondrial membrane and caspase-3 activation. Accordingly, mice lacking Gal-1 ( Lgals $\left.^{-/-}\right)$ have longer duodenal villi and exhibit a more pronounced deleterious response upon starvation compared with wildtype mice, suggesting that Gal-1 may be involved in overall regulation of enterocyte turnover in the villus, thus contributing to small bowel homeostasis.

\section{Results}

Co-expression of Gal-1 and Gal-1-binding sites in mouse small intestine correlates with a permissive 'glycosylation signature'. To understand the role of Gal1 -glycan interactions in mucosal microenvironments, we first assessed the expression of Gal-1 and specific glycan structures in mouse small intestine. Gal-1 expression was evaluated in intestinal cells at the mRNA and protein levels by qRT-PCR and immunoblot analysis, respectively (Figures $1 \mathrm{a}$ and b). Duodenal mouse cells showed considerable expression of this glycan-binding protein $(0.8 \mu \mathrm{g} / \mathrm{mg}$ protein or $3 \mu \mathrm{g} / \mathrm{g}$ wet intestinal tissue). Gal-1 was abundant within the lamina propria and muscularis mucosa (Figure 1c). To determine the distribution of specific glyco-receptors that might mediate the functions of this glycan-binding protein, Gal-1-binding sites were assessed by flow cytometry of mouse enterocytes using biotinylated rGal-1 (Figure 1d). Enterocytes displayed considerable expression of glycoepitopes that bound exogenous rGal-1. A dose-response curve of lectin binding analyzed by flow cytometry demonstrated that as low as $15 \mathrm{ng} / \mathrm{ml}$ Gal- 1 was sufficient to bind cell surface glycans on enterocytes (data not shown). Carbohydrate-dependent binding of rGal-1 was demonstrated by co-incubation with $100 \mathrm{mM}$ lactose, (Figure 1d). To determine the glycophenotype of small intestinal tissue, we used a panel of plant lectins that bind to specific glycan structures and determine susceptibility or resistance to Gal-1 (Figure 1e). Consistent with the extensive binding of Gal-1 to enterocytes in the tip of the villi, these cells also bound peanut agglutinin (PNA), a lectin that binds to asialo-galactose- $\beta 1-3-N$-acetylgalactosamine core- 1 $O$-glycans and marks the absence of $\alpha 2-3$ sialylation of core1 O-glycans, L-phytohemagglutinin (PHA-L), a lectin that recognizes $\beta 1,6-N$-acetylglucosamine-branched complex $N$-glycans and Lycopersicon esculentum (LEL), a lectin that recognizes polylactosamine-enriched glyco-epitopes. ${ }^{5}$ In line with this glyco-profile, we found no specific reactivity for the Sambucus nigra agglutinin (SNA), suggesting the absence of $\alpha 2-6$ sialylated-terminal glycans on epithelial cells. Collectively these results confirm the abundance of Gal-1 and Gal-1-binding sites within murine small intestine, suggesting a potential role for lectin-glycan lattices in modulating enterocyte homeostasis.
Gal-1 induces apoptotic death of mouse enterocytes. As Gal-1 has been reported to modulate the survival of distinct cell types, including $T$ cells and tumor cells, through induction of apoptosis, ${ }^{4,11,18,19}$ we examined the proapoptotic effects of this lectin on enterocytes isolated from mouse small bowel. Freshly isolated enterocytes were incubated in the presence of $10 \mu \mathrm{M}$ rGal-1 for 2, 4 and $16 \mathrm{~h}$ and binding of annexin $\mathrm{V}$ was analyzed as a marker of early apoptosis (Figure 2a). Isolated enterocytes exposed to rGal-1 showed increased annexin $\mathrm{V}$ staining in a time-dependent manner. Although enterocytes spontaneously underwent apoptosis after being extracted from the mucosa (time $=0$ ) (Figure 2a), annexin V staining intensity was higher in cells incubated with rGal-1 as incubation time was prolonged, as compared with controls cultured in medium alone. A percentage of cells incubated with rGal-1 were annexin $\mathrm{V}^{-}$suggesting that a restricted population of epithelial cells were resistant to the pro-apoptotic effects of this lectin. The frequency of $\mathrm{CD}^{+} \mathrm{T}$ cells in cell extracts was below $3 \%$ in all cases as analyzed by flow cytometry (data not shown). Interestingly, upon incubation with rGal-1 phosphatidylserine exposure occurred in a concentration- and saccharidedependent manner (Figure 2b). Apoptosis of enterocytes was evidenced by flow cytometry using the terminal deoxynucleotidyl transferase dUTP nick end labeling (TUNEL) assay (Figure 2c). Enterocytes treated with rGal-1 for $16 \mathrm{~h}$ showed an increased percentage of TUNEL-positive cells $(51 \pm 3.5$ versus $27.10 \pm 1$ compared with cells cultured with medium alone; $P<0.01$ ). Thus, exposure to Gal-1 engages an apoptotic program in mouse primary enterocytes.

Characterization of the Gal-1 apoptotic pathway in enterocytes. To further understand the mechanisms underlying Gal-1-induced cell death, isolated enterocytes were exposed to Gal-1 in the absence or presence of the ZVAD-FMK (benzyloxycarbonyl-Val-Ala-Asp (OMe) fluoromethylketone), a pan-caspase inhibitor (Figure 3a). Results showed a statistically significant inhibition of apoptosis induced by $\mathrm{Gal}-1$ in enterocytes previously exposed to ZVAD-FMK, suggesting that Gal-1-induced cell death proceeds through a caspase-dependent pathway. As clearly seen, not all cells isolated from the epithelial compartment underwent apoptosis in the presence of rGal-1, which reflects the differential sensitivity of some sub-populations to the effects of this glycan-binding protein. To investigate whether caspase-3 is involved in this pathway, cells cultured with rGal-1 for $16 \mathrm{~h}$ were lysed and caspase-3 activity was assessed using the specific fluorometric substrate Ac-DEVD-AFC ( $N$-acetyl-Asp-Glu-Val-Asp-AFC 7amino-4-trifluoromethyl coumarin) (Figure $3 b$ ). When cells were exposed to rGal-1, fluorescent staining increased in a dose-dependent manner, an effect which was almost completely prevented by co-incubation of Gal-1 with a caspase-3-specific inhibitor (DEVD-CHO) (Figure 3b). Our results indicate that Gal-1 signals a caspase-3dependent apoptotic pathway in enterocytes. To further evaluate upstream mediators involved in this apoptotic mechanism, we analyzed variations of the mitochondrial 
a

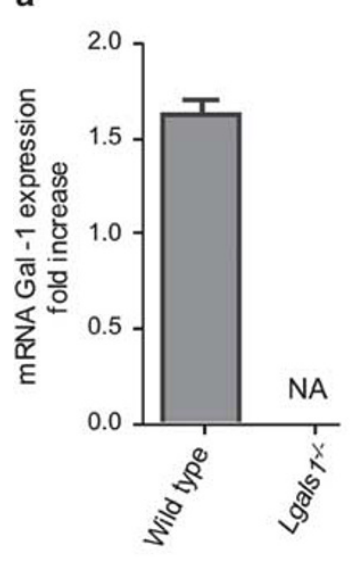

b
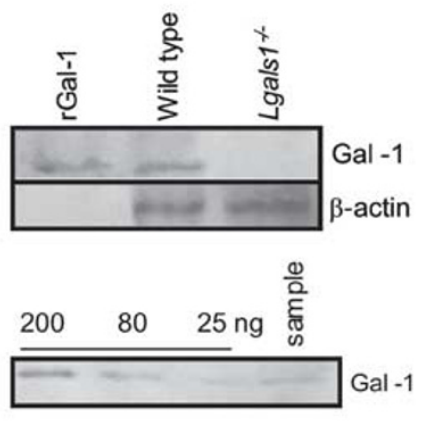

C $\quad$ Gal-1

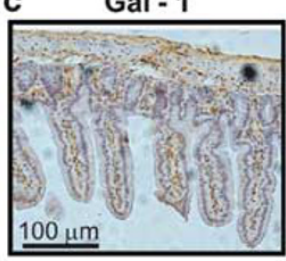

Control

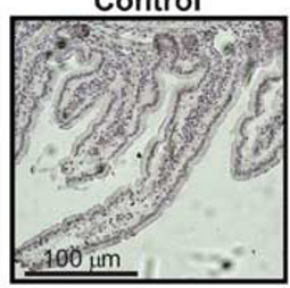

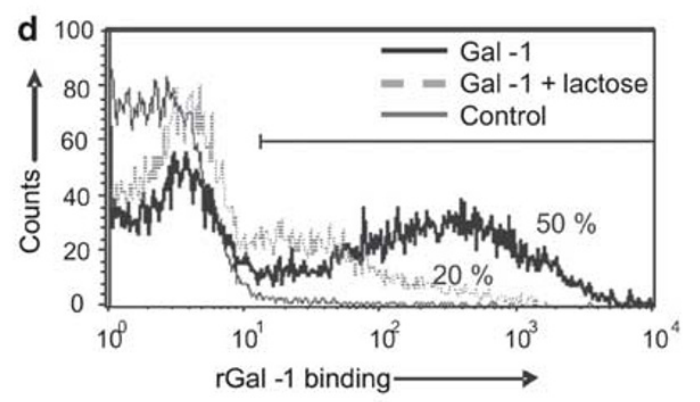

e

Gal - 1

PHA
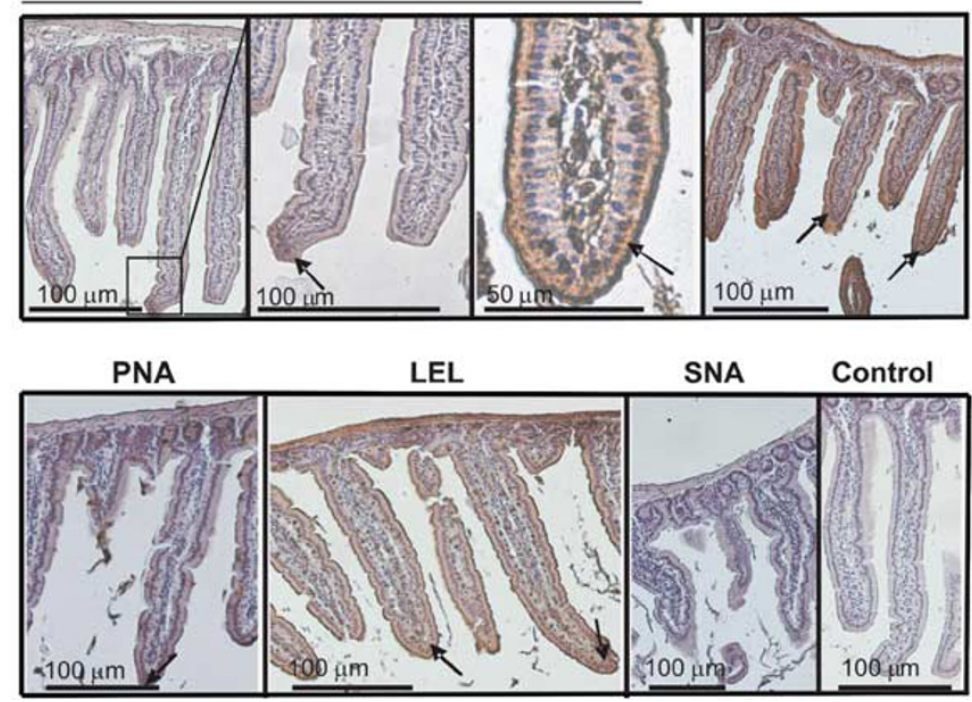

Figure 1 Expression of Gal-1 and Gal-1-binding sites in small bowel mouse mucosa. (a) Quantitative RT-PCR analysis of mRNA Gal-1 expression in duodenum of wildtype and $L$ gals $1^{-1-}$ mice. Results are expressed as fold increase of mRNA Gal-1 expression, standardized with mRNA $\beta$-actin expression (NA: no amplification). (b) Upper panel: immunoblot analysis of protein extracts obtained from duodenum of wild-type and $L$ gals $1^{-/}$mice; lower panel: immunoblotting for Gal-1 of duodenum from wild-type mouse (sample) and known quantities of rGal-1 (200-25 ng) to build a standard curve for quantification of relative Gal-1 concentration in tissues analyzed. (c) Immunohistochemistry of Gal-1 in duodenum of wild-type mice as revealed with a rabbit Gal-1 antiserum or non-immune rabbit serum as negative control. (d) Flow cytometry of Gal-1 binding to isolated mouse enterocytes. Biotinylated rGal-1 and streptavidin-APC were used with (dotted lines) or without $100 \mathrm{mM}$ lactose (black lines). As controls (gray lines) cells were only stained with streptavidin-APC. Percentages correspond to cells expresssing Gal-1-binding sites. (e) Glycophenotype of mouse duodenum was assayed using biotinylated lectins: Gal-1, PHA (as an indicator of $\beta 1,6$-branched complex N-glycans), PNA (indicating lack of terminal $\alpha 2-3$-linked sialic acid in core-1-Oglycans), LEL (indicating poly- $N$-acetyl-lactosamine sequences), SNA (indicating the presence of $\alpha 2-6$ sialic acid linked to terminal galactose). Negative controls were carried out by omitting incubation with the corresponding lectin. Arrows indicate lectin binding

membrane potential in enterocytes exposed to rGal-1 for 16 h. A significant percentage of cells displayed reduced mitochondrial membrane potential (higher green fluorescent and lower red fluorescence) (Figure 3c), suggesting a role of the mitochondrial pathway in Gal-1-induced enterocyte apoptosis. 
a

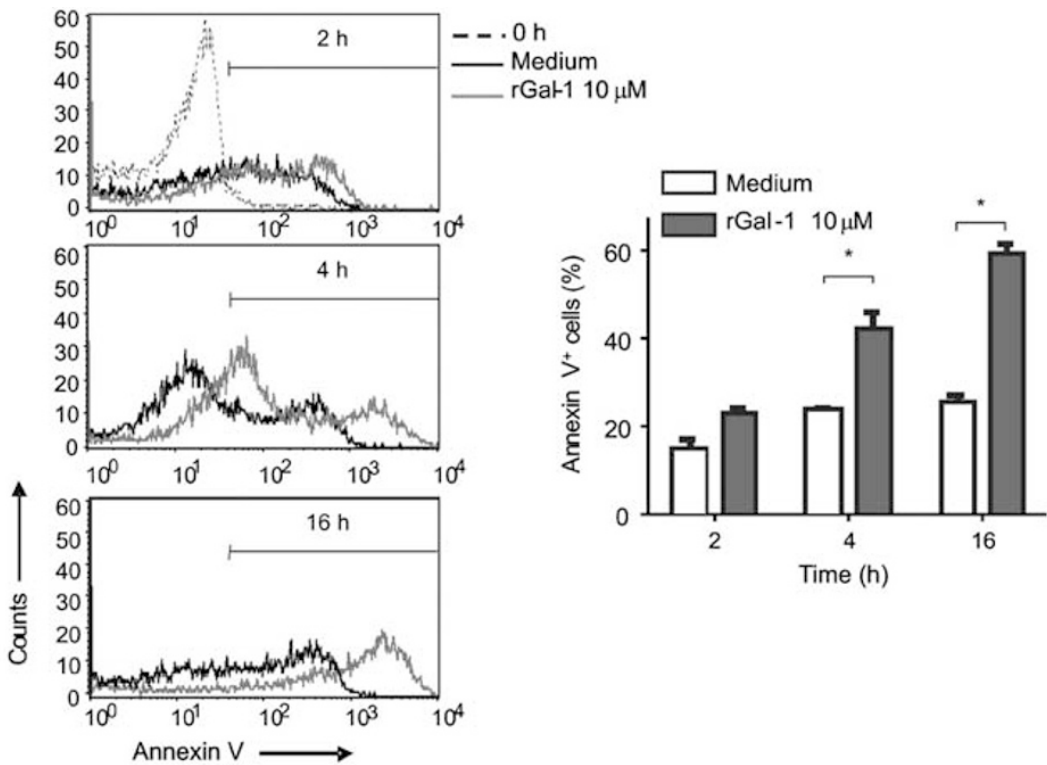

b

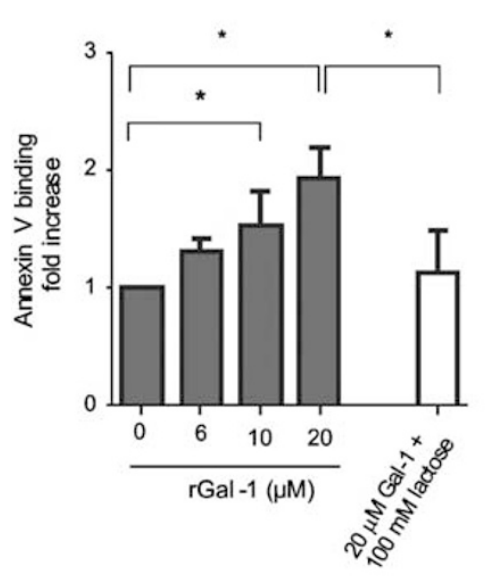

C
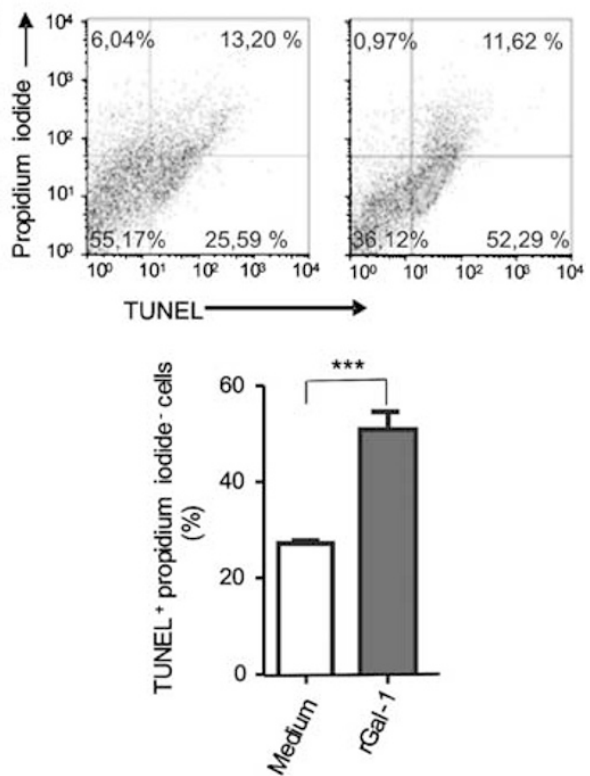

Figure 2 Gal-1 signals apoptosis in mouse enterocytes. (a) Epithelial cells isolated from duodenal mucosa were incubated with $10 \mu \mathrm{M}$ rGal-1 and annexin V binding was analyzed by flow cytometry. Left panel: enterocytes extracted at time zero (dashed line), black histogram corresponds to cells incubated with culture medium during different time periods and gray histogram corresponds to cells incubated with Gal-1 $10 \mu \mathrm{M}$. Right panel summarizes the results of four independent experiments; white column corresponds to cells incubated without rGal-1 whereas dark column corresponds to cells exposed to Gal-1 (mean values \pm S.E.M.). Statistically significant differences $P<0.05$ are denoted as starred values $\left(^{*}\right)$. (b) Phosphatidylserine exposure induced by rGal-1. Cells were incubated for $16 \mathrm{~h}$ with different concentrations of Gal-1 and analyzed by annexin $\mathrm{V}$ staining and flow cytometry. Data represent fold increase \pm S.E.M. of percentages of annexin $\mathrm{V}^{+}, \mathrm{PI}^{-}$cells relative to cells incubated with medium alone. Results correspond to eight independent experiments. Experiments were also carried out in the presence of $100 \mathrm{mM}$ lactose. Statistically significant differences $P<0.05$ are denoted as starred values $\left({ }^{*}\right)$. (c) Apoptosis of enterocytes induced by rGal-1 as shown by TUNEL assay and flow cytometry. Cells were incubated with medium (upper left panel) or with $10 \mu \mathrm{M}$ Gal-1 during $16 \mathrm{~h}$ (upper right panel). Data are representative of four independent experiments giving similar results. Data in the bottom panel show the mean value \pm S.E.M. of four parallel and independent experiments $\left({ }^{* \star \star} P<0.01\right)$

\section{Exogenous Gal-1 promotes mouse enterocyte apoptosis}

in vivo. To directly assess the physiologic relevance of Gal1-induced apoptosis in vivo, ligated loop assays were performed. Mice were treated with a duodenal intralumenal injection of rGal-1, saline or BSA as a control protein. After $3 \mathrm{~h}$, anesthetized animals were killed, the small intestine was excised and enterocytes were isolated. A statistically significant induction of apoptosis was achieved with $20 \mu \mathrm{M}$
rGal-1 (Figure 4a). However, when mice were treated with the same concentration of BSA or saline solution no binding of annexin $\mathrm{V}$ was detected (Figure 4a). Moreover, similar results were obtained using $L g a l s 1^{-/-}$mice, suggesting lack of contribution of endogenous over exogenous Gal-1 in enterocyte viability. To determine whether phosphatidylserine exposure was accompanied by execution of a full apoptotic program, TUNEL assay was carried out on 
a

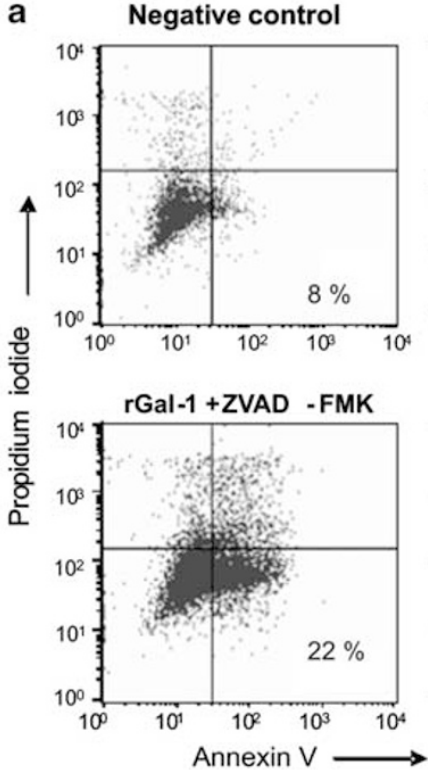

Positive control

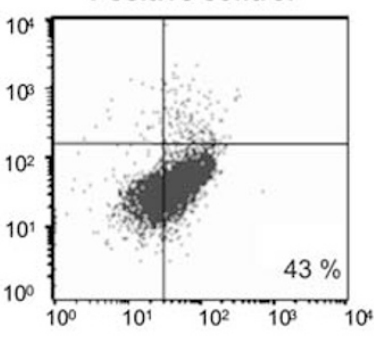

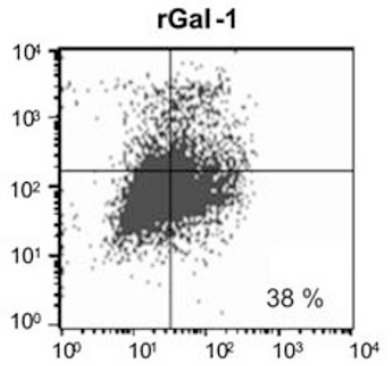
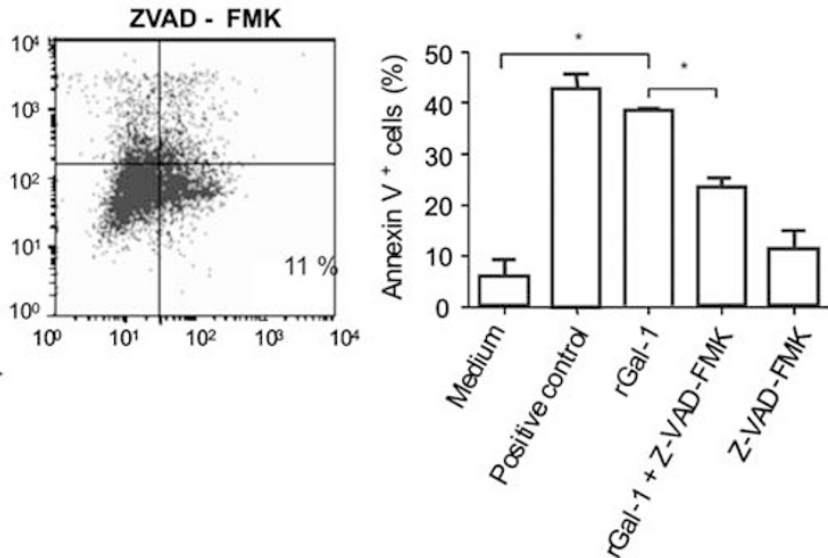

b

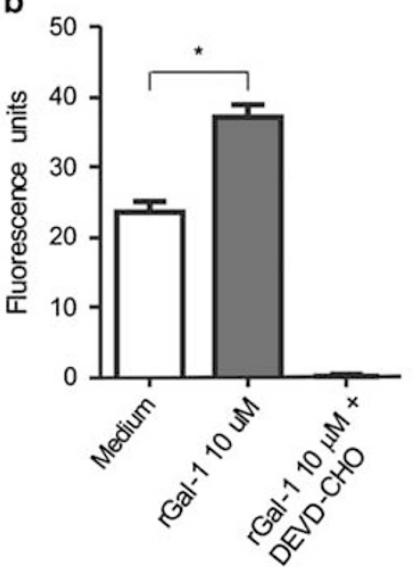

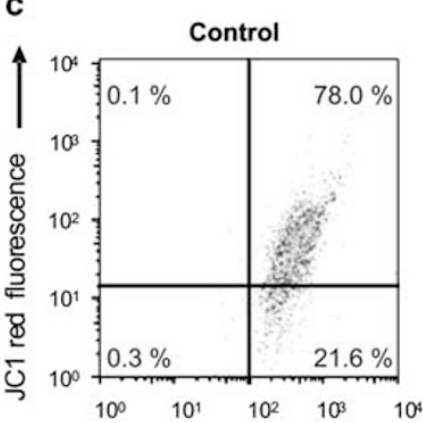

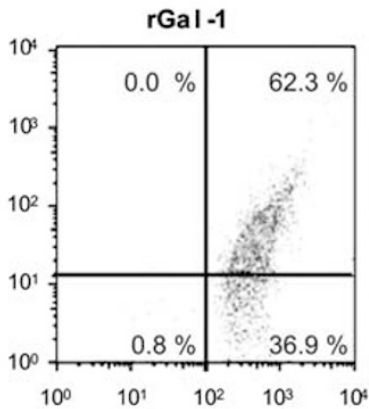

JC1 greenfluorescence

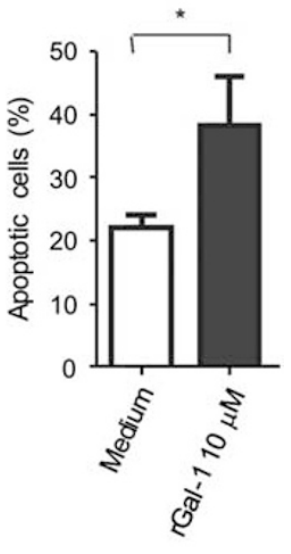

Figure 3 Mechanisms underlying Gal-1-induced enterocyte apoptosis. (a) Flow cytometry analysis of annexin V/PI staining of enterocytes cultured for $16 \mathrm{~h}$ with different stimuli. Enterocytes were incubated with medium plus FBS (negative control), with medium without FBS (apoptosis positive control, with $10 \mu \mathrm{M}$ rGal-1, with rGal-1 $10 \mu \mathrm{M}$ before incubation for $2 \mathrm{~h}$ with ZVAD-FMK (a pan-caspase inhibitor) or with medium before incubation for $2 \mathrm{~h}$ with ZVAD-FMK. Results are from one representative of four independent experiments. The accompanying graph shows average percentage of annexin $\mathrm{V}^{+} / \mathrm{PI}^{-}$cells from all experiments. Statistically significant differences of $P<0.05$ are denoted as starred values ( $\left.{ }^{*}\right)$. (b) Enzymatic activity of caspase-3 was determined with the caspase-3 specific fluorometric substrate Ac-DEVD-AFC. Enterocytes were incubated with $10 \mu \mathrm{M} \mathrm{rGal}-1$ for $16 \mathrm{~h}$ and then harvested, lysed and analyzed. DEVD-CHO is a caspase-3-specific inhibitor. Data are results of four independent experiments (mean value \pm S.E.M.). ${ }^{*} P<0.05$. (c) Alteration of the mitochondrial membrane potential in enterocytes incubated for $16 \mathrm{~h}$ with medium alone (negative control, left dot plot) or with $10 \mu \mathrm{M}$ rGal-1 (right dot plot). Data are results of four independent experiments. ${ }^{*} P<0.05$

intestinal samples by inmunofluorescence (Figure 4b). Few apoptotic cells could be detected in loops filled with saline (1-2 nuclei per 5 villi) or with BSA (not shown). Although few apoptotic cells were observed within the lamina propria, most TUNEL-positive nuclei were detected in the epithelial cell compartment of loops filled with rGal-1. Notably, most of TUNEL-positive epithelial cells were located in the tip of the villi (showed by arrows). These results indicate that mouse enterocytes are sensitive to in vivo induction of apoptosis by Gal-1. Of note, the frequency of TUNEL-positive cells was similar between $\mathrm{Lgals} 1^{-/}$and wild-type mice filled with saline or rGal-1 in ligated loop assays (data not shown).

Endogenous Gal-1 controls mice villus length. It has been demonstrated that enterocytes located on the tip of the villus undergo apoptosis and shedding, and this effect may influence the length of the villus. ${ }^{20}$ We studied the potential role of endogenous Gal-1 in modulating mouse enterocyte apoptosis, and hence the villus length using duodenum from wild-type and $L g a l s 1^{-/-}$mice. Samples were routinely fixed, 

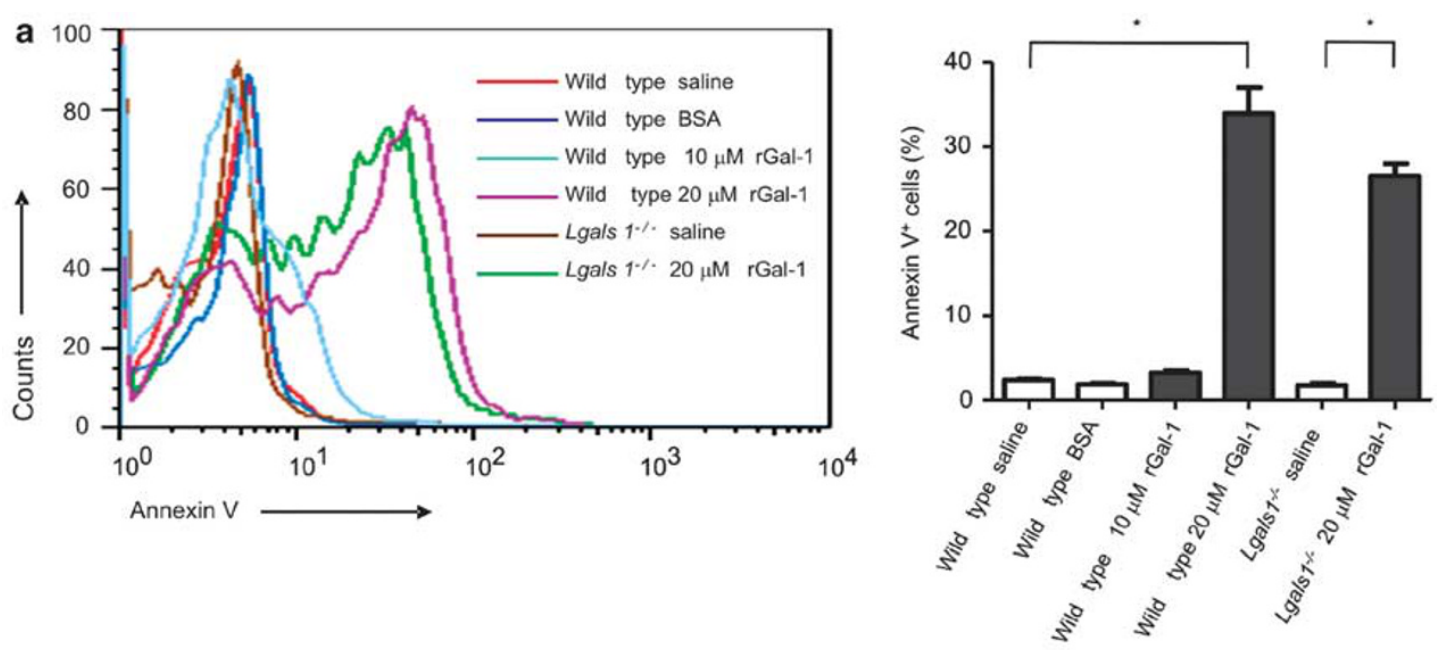

b
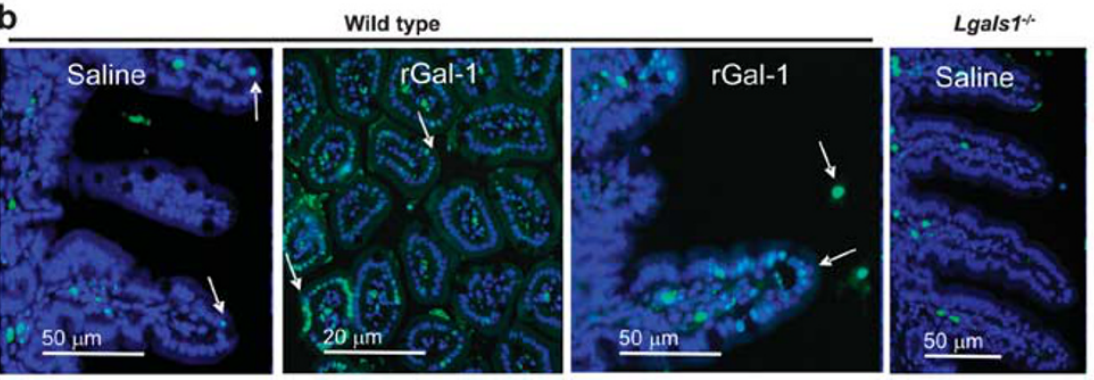

Figure 4 Gal-1-mediated induction of enterocyte apoptosis in vivo. (a) Flow cytometry analysis of annexin V and PI staining in cells obtained from duodenal ligated loops. Results correspond to cells isolated from either wild-type or $\mathrm{Lgals}^{-1-}$ mice that had ligated loops filled with saline, $10 \mu \mathrm{M} \mathrm{rGal}-1,20 \mu \mathrm{M}$ rGal-1 or the same concentration of BSA as indicated. The histogram shows representative results out of four separate experiments: ${ }^{*} P<0.05$. (b) TUNEL assay of ligated loops corresponding to wild-type and Lgals $1^{-1-}$ mice filled with saline or rGal-1 $20 \mu \mathrm{M}$. TUNEL-positive nuclei appear in cyan (arrows). Background shows DAPI staining. Results are representative of three independent experiments

stained with haematoxilin/eosin and visualized by optical microscopy. Although villus morphology was similar in wildtype and $L$ gals $1^{-1-}$ mice, villus from Gal-1-deficient mice was significantly longer $(P<0.002)$ (Figure 5a), indicating a potential role of endogenous Gal-1 in modulating epithelial cell survival. Of note, no significant histological differences were observed in other organs studied (liver, kidney, heart, thymus, lung, spleen) (data not shown). To rule out the possibility that longer villi in $\operatorname{Lgals1^{--}}$ mice could be associated with an increased proliferative response in the crypts, we performed an in vivo assay with BrdU and the binding to FITC-labeled anti-BrdU was analyzed by flow cytometry. No statistical difference could be observed in the percentage of BrdU-positive cells between Lgals $1^{-1-}$ and wild-type mice (17.1 \pm 1.8 versus $16.7 \pm 0.6$, respectively) (Figure $5 b$ ). When proliferation cell nuclear antigen (PCNA) was analyzed by immunohistochemistry, positive cells were observed in the crypt of all samples and no statistical difference was observed when comparing wild-type versus $L$ gals $1^{-1}$ mice (10.16 \pm 2.11 versus $9.58 \pm 1.08$ cells/crypt, respectively) (data not shown). Thus, endogenous Gal-1 regulates villus length through mechanisms involving modulation of cell death rather than proliferation of epithelial cells.

Starvation differentially modulates villus length in wild-type and Lgals $1^{-\prime}$ mice. To further evaluate the pathophysiologic relevance of our findings, animals were starved for $48 \mathrm{~h}$ as this process conditions mouse enterocytes to engage apoptotic programs. ${ }^{21}$ Compared with fasted $\mathrm{Lgals} 1^{-/}$mice, fasted wild-type mice showed reduced villus length and a diminished small intestine weight in response to starvation (Figures $6 \mathrm{a}-\mathrm{c}$ ). However, no significant differences were observed in villi length and intestine weight between fasted and ad libitum fed $\mathrm{Lgals1^{-/ }}$ mice. Enterocyte apoptosis was also evaluated using annexin $\mathrm{V}$ staining. The percentage of annexin $\mathrm{V}$ positive cells was significantly higher in wild-type fasted mice as compared with $L$ gals $1^{-1-}$ counterparts, consistent with reduced villus length and intestinal weight data (Figure 6d). In addition, we observed an increase in induction of Lgals1 transcript (1.25-fold increase) and Gal-1 protein (1.7-fold increase) in fasted versus ad libitum fed wild-type mice as determined by qRT-PCR (Figure 6e) and immunoblot analysis (data not shown). These results demonstrate that endogenous Gal-1 is required for epithelial cell survival and response to starvation.

Gal-1 induces apoptosis of human enterocytes. Given the potential biomedical implications of our findings, we then sought to examine the effect of Gal-1 in the induction of apoptosis of human yeyunum enterocytes. Surgical specimens of normal human small bowel were employed 

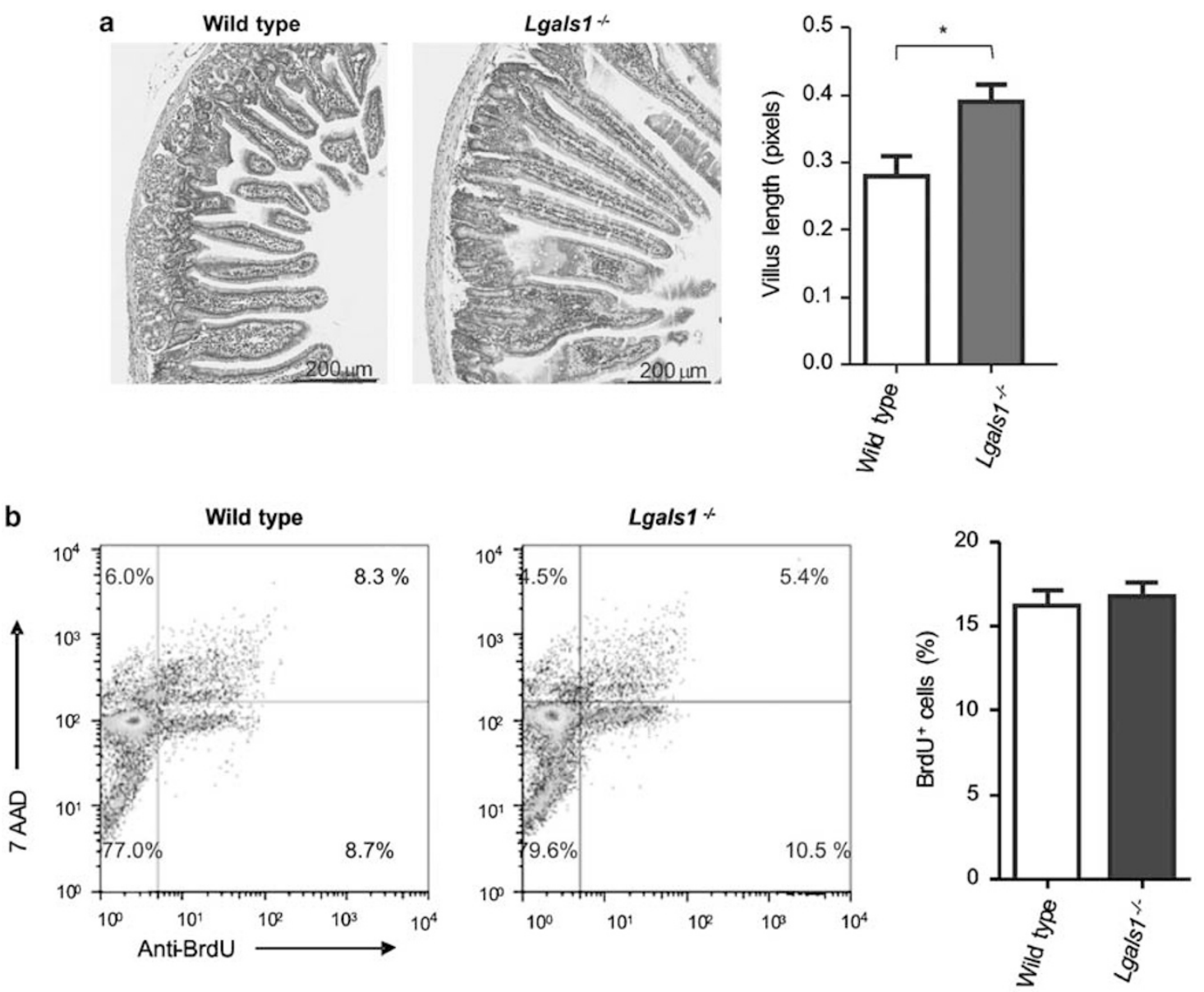

Figure 5 Role of endogenous Gal-1 in regulating villi length. (a) Haematoxylin-eosin staining of intestinal samples from wild-type $(n=15)$ and $L g a l s 1^{-/-}(n=15)$ mice. ${ }^{*} P<0.002$. Ten sections per duodenum were analyzed. (b) Analysis of anti-BrdU-FITC and 7-AAD by flow cytometry of isolated intestinal epithelial cells obtained from wild type and $\operatorname{Lgals} 1^{-1-}$ mice

and enterocytes were detached from the mucosa and analyzed by fluorescence microscopy. Apoptosis was assessed by staining isolated cells with ethidium bromide and acrydine orange upon incubation with rGal-1 (Figure 7a). The basal percentages of apoptotic and necrotic cells were highly variable among samples $(20 \pm 10 \%$ apoptotic cells and $10 \pm 8 \%$ necrotic cells). Notably, incubation of isolated enterocytes with $\mathrm{rGal}-1$ for $16 \mathrm{~h}$ yielded a highly significant percentage of apoptotic cells ( $90 \pm 2 \%)$. When assessed by flow cytometry, Gal-1 induced apoptosis of human enterocytes in a dose-dependent manner (Figures 7b and c). These results indicate that human enterocytes are highly sensitive to the pro-apoptotic effect of this glycan-binding protein.

\section{Discussion}

The homeostasis of the intestinal epithelium requires tight control and balance of the different processes of proliferation, differentiation, migration and apoptosis. This coordination requires intervention of multiple synchronized pathways. The epithelial compartment of the gut encompasses a high cell turnover and the preservation of normal morphology and function relies on a delicate balance between cell proliferation and death. ${ }^{20}$ Several mechanisms have been proposed to operate in enterocyte maturation and apoptosis along the crypt-villus axis. In fact, there are two main compartments where apoptosis is physiologically relevant: at the crypt level, to remove excess or unwanted stem cells, and at the tip of the villus to limit their life span and control villus length. ${ }^{20}$

As protein-glycan interactions have recently emerged as critical mediators of intestinal cell physiology and pathology, ${ }^{22,23}$ here we investigated the role of Gal-1 in the induction of apoptosis of intestinal epithelial cells, mainly in senescent epithelial cells located near the top of the villus. ${ }^{20}$ We provide evidence on the role of Gal-1-glycan lattices in human and mouse enterocyte apoptosis. Induction of apoptosis by this glycan-binding protein has been widely described in a variety of cell subsets. ${ }^{4,5,10}$ Susceptibility of T cells to Gal-1-induced cell death has been well established and characterized in normal and pathological conditions, and it has been proposed to be regulated via Fas-dependent or -independent pathways. ${ }^{5,18,19} \mathrm{~B}$ cell lymphoma cells, ${ }^{24}$ and non-immune cells such as Leydig cells, ${ }^{25}$ prostate cancer cells, ${ }^{26}$ breast cancer cells and trophoblast tumors, ${ }^{27}$ have also found to be targets of the pro-apoptotic effects of Gal-1. Regarding intestinal 
a
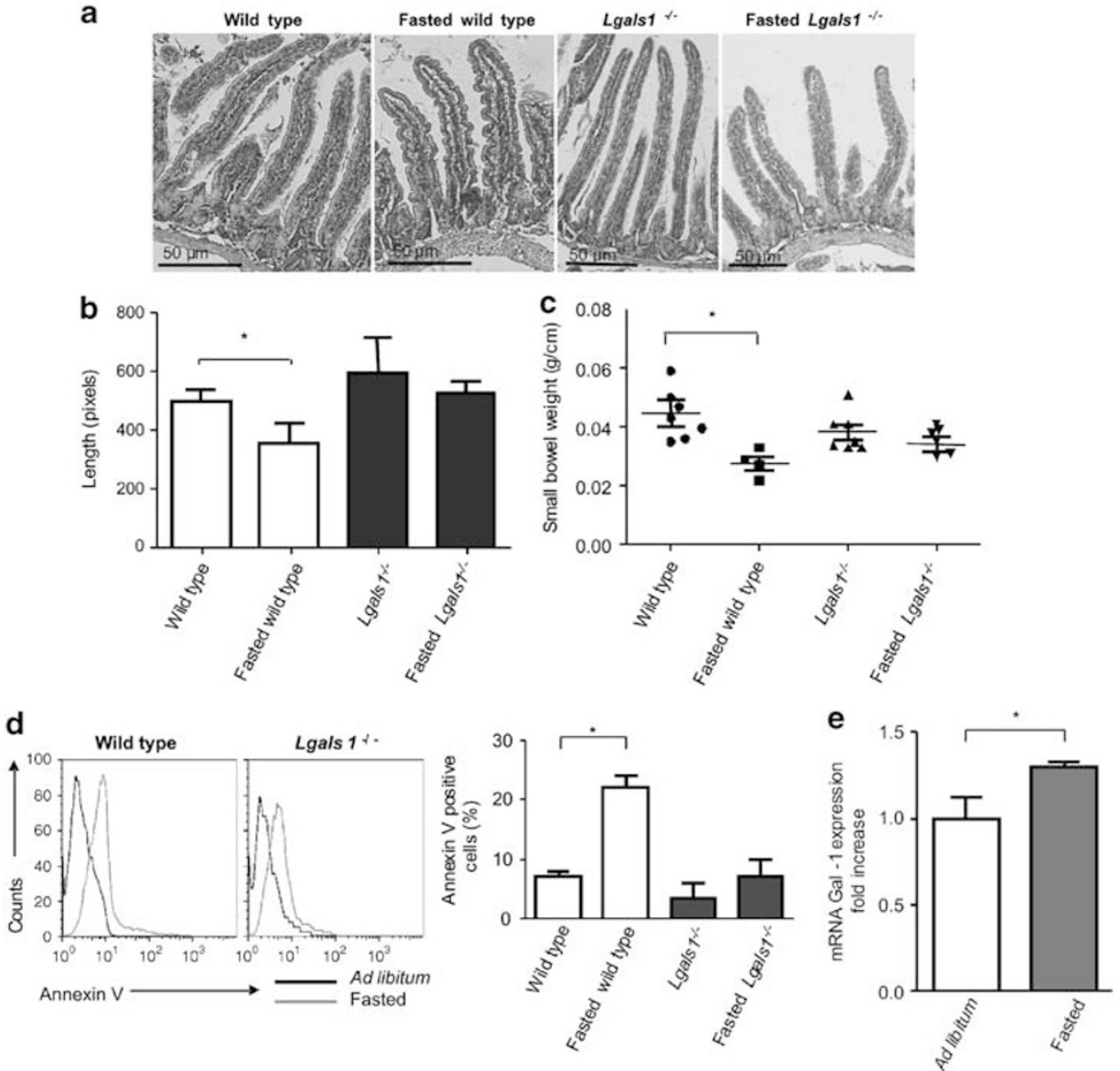

Figure 6 Role of endogenous Gal-1 in regulating epithelial cell survival in vivo following starvation. Wild-type and $L g a l s 1^{-/-}$mice were starved during $48 \mathrm{~h}$ and intestinal specimens were analyzed. (a) Haematoxylin-eosin staining of representative small bowel longitudinal sections of wild-type and $L$ gals $1^{-/-}$mice corresponding to ad libitum fed mice and fasted mice. Magnification $\times 20$ (a and $\mathbf{b})$ and $\times 10$ (c and d). (b) Statistical analysis corresponding to villi length ( $\left.{ }^{*} P<0.05\right)$. Data are expressed as mean values \pm S.E.M. $(n=10)$. (c) Statistical analysis corresponding to small bowel weight $\left({ }^{*} P<0.05\right)$. Data are expressed as mean values \pm S.E.M. ( $\left.n=7\right)$. (d) Annexin $V$ staining of enterocytes collected from wild-type and $\mathrm{Lgals}^{-1-}$ fasted and ad libitum fed mice. Right: statistical analysis of results obtained with three mice of each group $\left({ }^{\star} P<0.05\right)$. (e) Quantitative RT-PCR analysis of mRNA Gal-1 expression in duodenum of wild-type ad libitum fed and fasted mice. Results are expressed as fold increase of mRNA Gal-1 expression, standardized with $\beta$-actin mRNA expression $\left({ }^{*} P<0.05\right)$

cells, human colonic Caco-2 cells have been proposed to be susceptible to Gal-1-induced cell death, although the precise mechanisms and physiologic relevance of these findings have not yet been characterized. ${ }^{28}$ In the present study we provide the first evidence showing a role for Gal-1 in modulating the survival of human and mouse enterocytes isolated from the small bowel; this mechanism could influence the maturation process of these cells during their migration from the crypt to the tip of the villus. In this regard, it appears that the glycosylation machinery generates a differential array of cell surface glycans along the crypt/villus axis, which makes these cells sensitive to Gal-1-induced cell death. The synthesis of these glycan structures occurs via a complex and highly regulated process involving glycosyltransferases and glycosidases. ${ }^{4}$ Mechanisms of Gal-1-mediated death have been shown to vary among different cell types. ${ }^{11,18,19,25}$ Using in vitro assays, we demonstrated using isolated epithelial cells that apoptosis is dependent on caspase activation, through the intrinsic mitochondrial pathway. Paclik et $a l .^{28}$ reported a calpain-dependent, caspase-independent, induction of apoptosis by Gal-1 in the tumor Caco-2 cell line. ${ }^{29}$ These results could be relevant in the context of genes that control apoptosis during colorectal cancer. ${ }^{30}$

Interestingly, we found that Gal-1 induces apoptosis of a discrete population of enterocytes. TUNEL-positive cells were detected in the tip of the villi when apoptosis was induced in vivo following administration of rGal-1. Strikingly, we found that $L g a l s 1^{-1-}$ mice exhibited longer villi as compared with wild type mice, which did not appear to be related to differences in cell proliferation. Moreover, when mice were subjected to physiologic stress (fasting during $48 \mathrm{~h}$ ), animals devoid of Gal-1 did not significantly afford reduction of villus length and small bowel weight, as compared with their wild-type counterpart.

The glycosylation profile of cell surface glycoproteins and glycolipids can differ considerably among different gut cell populations, when compared with similar cell subsets from other organs and tissues. ${ }^{31}$ This effect might be probably related to the particular tolerogenic microenvironment prevalent in the gut, which imposes a differential glyco-profile 


\section{a Live enterocytes}
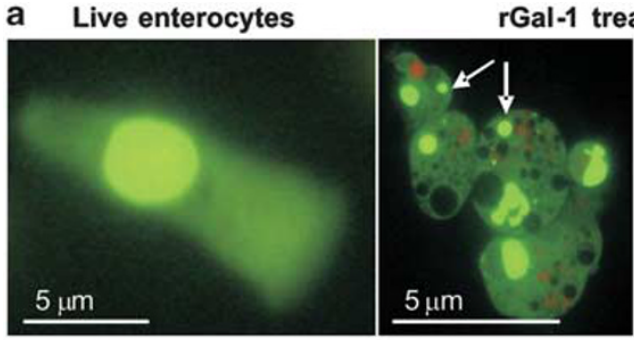

b

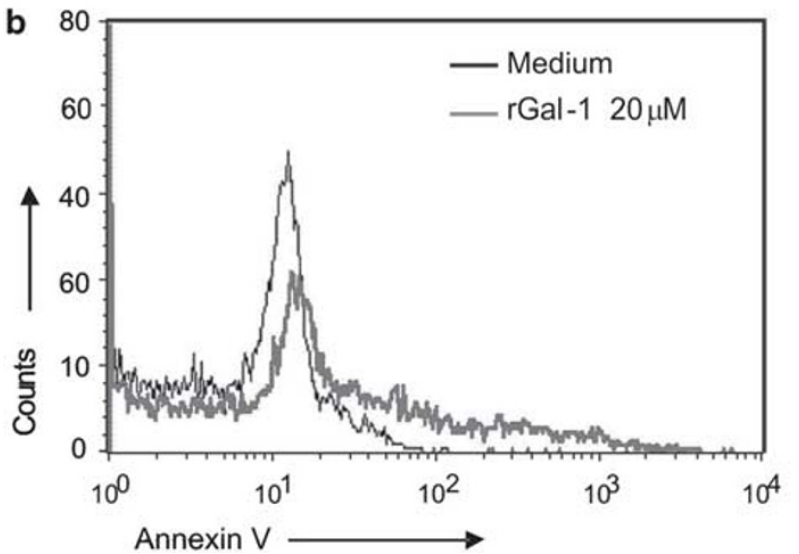

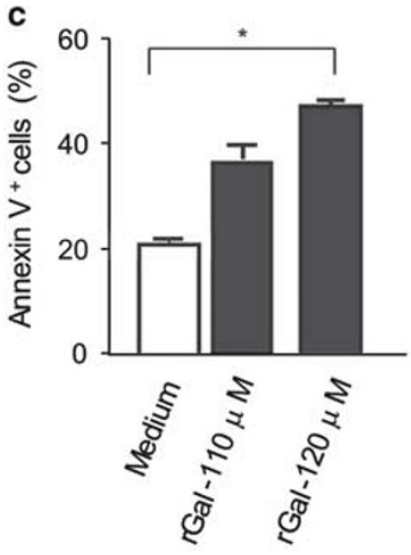

Figure 7 Gal-1 triggers apoptotic death in human enterocytes. (a) Ethidium bromide and acridine orange staining of human enterocytes by fluorescence microscopy. Live enterocytes at initial time (left panel); isolated enterocytes exposed to $10 \mu \mathrm{M} \mathrm{rGal-1}$ for $16 \mathrm{~h}$ where a majority of apoptotic enterocytes (brilliant green or orange nucleus) can be observed (middle panels) and necrotic enterocytes (right panel). (b) Flow cytometry analysis of annexin V and PI staining of enterocytes incubated with medium alone or $10 \mu \mathrm{M}$ rGal-1. (c) Mean values of percentages of annexin $V$ positive cells. ${ }^{*} P<0.05$. The results shown are representative of four independent experiments

through enhanced activity of sialyltransferases. ${ }^{22,31}$ In the present work, by using biotinylated lectins, we found that enterocytes display a glycosylation profile characterized by the absence of $\alpha 2-3$ sialylation of core- 1 O-glycans (PNA ${ }^{+}$ cells), $\beta 1,6$-branched complex $N$-glycans ( $\mathrm{L}-\mathrm{PHA}^{+}$cells) and poly- $N$-acetyl-lactosamine sequences ( $\mathrm{LEL}^{+}$cells) as well as the absence of $\alpha 2,6$-linked terminal sialic acid (SNA ${ }^{-}$cells). Interestingly, this phenotype is consistent with a glycosylation signature permissive for Gal-1 binding and subsequent cell death, as it has been demonstrated for the T-cell compartment. $^{5}$ However, this glycophenotype may differ in an inflammatory setting where the balance between cell proliferation and apoptosis is altered. ${ }^{7}$ Although different molecular pathways have been proposed, ${ }^{32,33}$ the mechanisms underlying cell death during inflammatory processes still remain uncertain. In this regard, the influence of glycosylation and the regulatory effect of glycan-binding proteins have not been carefully studied in the epithelial cell compartment.

In this study, we showed that Gal-1 induces apoptosis both in vitro and in vivo, a process that was prevented by addition of the specific disaccharide lactose. This suggests that cell viability may be dependent on the glycosylation status of epithelial cell surface receptors and may be spatio-temporally regulated during the differentiation of these cells along the crypt-villus axis. Although basal levels of apoptosis were observed once epithelial cells underwent anoikis, a concentration- and time-dependent induction of cell death was observed in cells exposed in vivo (ligated loop assay) or in vitro to $\mathrm{rGal}-1$.
Regarding the source of endogenous Gal-1, this lectin has been reported to be distributed within the whole mammalian digestive tract. Human gut expresses Gal-1 both in the epithelial compartment and in the lamina propria. ${ }^{13}$ In the mouse gut, this lectin is expressed diffusely in the lamina propria as well as in the muscle layer. ${ }^{34}$ However, the production of Gal-1 in the epithelial compartment is rather controversial. ${ }^{15,34,35}$ Mathieu et al. ${ }^{14}$ reported a differential distribution of this lectin that is highly dependent on the mouse strain analyzed. We found that intestinal cells belonging to mouse 129/SvJ strain express substantial amounts of Gal-1 and Gal-1-binding sites.

Remarkably, Gal-1 substantially decreased in TNBSinduced colitis, an effect that positively correlated with inappropriate mucosal $\mathrm{T}$ cell accumulation and resistance of lamina propria T cells to apoptosis, ${ }^{7}$ suggesting that Gal-1glycan lattices may have a role in maintaining epithelialimmune homeostasis and integrity of intestinal mucosa. Our results indicate that Gal-1 serves as a key soluble factor involved in regulation of epithelial cell turnover and gut homeostasis. Lgals $1^{-/-}$mice showed longer villi and wildtype mouse small intestine showed an altered response upon starvation. Overall, these results suggest that endogenous Gal-1 is implicated in the regulation of enterocyte viability under physiologic or stress situations. Remarkably, cell proliferation rate was found to be equivalent in wild-type and Lgals $1^{-/}$mice, suggesting that this process does not constitute a compensatory mechanism to restore the homeostatic environment. 
In conclusion, our findings indicate for the first time that endogenous Gal-1 can execute an apoptotic program on human and mouse enterocytes, through activation of the mitochondrial pathway of cell death and this effect is more pronounced once the cell reaches the tip of the villus. This process may be critical in maintaining the integrity of the villus and sustaining the epithelial barrier function, thus favoring immune cell homeostasis and nutrient absorption. However, many questions still need to be addressed to further dissect the role of Gal-1-glycan interactions in different pathologic conditions of the gastrointestinal tract in which apoptosis contributes to disease pathogenesis, or is involved in the normal clearance of damaged cells (cancer, IBD, celiac disease or infectious diseases). ${ }^{32,33,36,37}$

\begin{abstract}
Materials and Methods
Intestinal epithelial cells. Cells were obtained from human and mouse small bowel. Wild-type and Lgals1 ${ }^{-1-}$ mice used in this study were of $129 / \mathrm{SvJ}$ background. Lgals $1^{-/}$mice were kindly provided by F Poirier (Institut Jacques Monod, Paris). Mice were bred at the animal facility of the Faculty of Exact Sciences, National University of La Plata according to institutional guidelines. The duodenum was washed, opened longitudinally and incubated for $10 \mathrm{~min}$ at $4{ }^{\circ} \mathrm{C}$ in buffer $\mathrm{A}$ (Hank's buffered saline solution (HBSS) supplemented with $100 \mathrm{IU} / \mathrm{ml}$ penicillin, $100 \mathrm{mg} / \mathrm{ml} \mathrm{streptomycin} \mathrm{and} 2 \%$ equine serum) with $1 \mathrm{mM}$ dithiotreitol and then, with fresh buffer A plus $0.5 \mathrm{mM}$ EDTA for $20 \mathrm{~min}$ at $37^{\circ} \mathrm{C}$ with vigorous shaking. Cells were immediately resuspended in RPMI supplemented with $5 \%$ fetal bovine serum (FBS), penicillin/streptomycin and gentamicin. All protocols were approved by the Ethics Committee of the School of Exact Sciences, National University of La Plata.

Intestinal human resection specimens were obtained with the consent of patients undergoing gut transplantation at Fundación Favaloro (Buenos Aires, Argentina) according to Institutional Review Board guidelines for the use of human tissue. Tissue was collected onto ice-cold HBSS supplemented with penicillin/streptomycin until use. The mucosal layer was mechanically removed, washed with HBSS and incubated in HBSS/penicillin/streptomycin plus $0.5 \mathrm{mM}$ EDTA. Cells were pelleted, resuspended in RPMI supplemented with 5\% FBS, penicillin/streptomycin and used immediately.
\end{abstract}

Immunoblot analysis. Tissues were homogenized and cells were lysed as described previously. ${ }^{38}$ Samples were assayed for the presence of Gal- 1 by using a $12 \%$ SDS-PAGE under reducing conditions (total protein load was $30 \mu \mathrm{g}$ per lane) and immunoblotted with rabbit specific antiserum obtained as described before (dilution 1:3000), followed by horseradish peroxidase-conjugated goat anti-rabbit IgG. Membranes were stripped and probed for $\beta$-actin (rabbit anti-mouse $\beta$-actin antibody, diluted 1:4000, AbCam Cambridge, UK) as a loading control. Immunoblots were visualized with the ECL Plus System (GE Healthcare, Bucks, UK) according to manufacturer's instructions. The bands were scanned and quantified using the Adobe Photoshop CS software (version 8.0.1).

Real time RT-PCR. Total RNA extraction was performed using the NucleoSpin RNA II kit (Macherey-Nagel, Dueren, Germany). Reverse transcription was performed using random primers and MMLV-Reverse transcriptase (Invitrogen, Carlsbad, CA, USA). qPCR was performed following manufacturer's protocol using the iCycler thermal cycler (Bio-Rad, Hercules, CA, USA). Primer sequences for Gal-1 were used as described. ${ }^{6}$ Fold difference was represented by the ratio of the normalized value of each sample to that of mouse $\beta$-actin. ${ }^{39}$

Histology and immunohistochemistry. Mouse intestines were fixed in $5 \%$ neutral-buffered formalin and embedded in paraffin. Samples were cut and mounted onto positive-charged glass slides and heated at $60^{\circ} \mathrm{C}$ for $30 \mathrm{~min}$. Briefly, xylene and ethanol were used to de-paraffinize and endogenous peroxidase activity was blocked with $3 \% \mathrm{H}_{2} \mathrm{O}_{2}$ /methanol. Antigen retrieval was performed in buffer citrate ( $\mathrm{pH} \mathrm{6.0)}$ and slides were microwaved. Non-specific sites were blocked with $1 \%$ BSA in PBS and incubated with primary and secondary antibodies. Counterstaining with 10\% hematoxylin was performed and sections were mounted with Eukit. For routine histological examination, the length of duodenal villi was assessed using an ocular micrometer. The length of 10 well-oriented villi with both side-crypts visible was measured per cross-section, and the mean length was calculated. At least five sections per animal were analyzed.

PCNA was assessed as a nuclear marker of DNA synthesis and proliferation, ${ }^{40}$ using a specific anti-PCNA antibody (Santa Cruz, Santa Cruz, CA, USA), followed by an anti-rabbit IgG-biotin and strepavidin-HRP (Sigma, St. Louis, MO, USA). Immunostaining was then revealed using 3,3'-diaminobenzidine tetrahydrochloride (DAB) chromogen (DAKO, Glostrup, Denmark).

Lectin histochemistry was performed using biotinylated lectins as the primary binding reagent: SNA, PNA, Lycopersicon esculentum lectin (LEL) and Phaseolus vulgaris agglutinin (PHA) were all from Vector Labs (Edelberry; Burlingame, CA, USA) and used at a concentration of $25 \mu \mathrm{g} / \mathrm{ml}$. Recombinant Gal-1 (rGal-1) $(3 \mu \mathrm{g} /$ $\mathrm{ml}$ ) was biotinylated as described. ${ }^{5,18}$ Streptavidin-HRP (DAKO) was then used as a secondary reagent and DAB was employed for the staining. Controls were performed by omitting the biotinylated lectins.

Immunohistochemistry for Gal-1 was carried out using a rabbit antiserum specific to Gal-1 obtained as described (dilution 1/3000). Primary antibody was incubated overnight at $4{ }^{\circ} \mathrm{C}$ and then goat anti-rabbit IgG conjugated to HRP (DAKO) was used for $1 \mathrm{~h}$ at $37^{\circ} \mathrm{C}$ (dilution 1/3000). Finally, sections were incubated with DAB. Control with non-immune serum as primary antibody was performed.

TUNEL assay was performed essentially as described by the manufacturer (Promega, Madison, WI, USA). Nuclei were counterstained with DAPI and apoptotic cells were visualized by fluorescence microscopy.

Galectin binding assay. Gal-1 binding to enterocytes was performed by flow cytometry using decreasing concentrations of biotinylated Gal-1 ranging from $15 \mu \mathrm{g} / \mathrm{ml}-1.5 \mathrm{ng} / \mathrm{ml}$ followed by addition of streptavidin-APC (BD Pharmingen, Franklin Lakes, NJ, USA). Controls were included either by omitting the biotinylated lectin or by performing binding assays in the presence of $100 \mathrm{mM}$ lactose.

Apoptosis assays. Freshly isolated enterocytes were incubated in RPMI 1640 medium supplemented with $5 \% \mathrm{FBS}$, penicillin/streptomycin at $37^{\circ} \mathrm{C}$ in a humidified $5 \% \mathrm{CO}_{2}$ atmosphere with different concentrations of rGal-1 during 2, 4 or $16 \mathrm{~h}$. Saccharide-dependent binding of Gal-1 to enterocytes was assessed in the presence of $100 \mathrm{mM}$ lactose as described. ${ }^{18}$ To analyze the mechanisms underlying epithelial cell death, cells were pre-treated with the pan-caspase inhibitor ZVADFMK (R\&D Systems, Minneapolis, MN, USA). Controls included dimethyl sulfoxide (vehicle). As positive controls, cell death was induced with serum-deprived medium or with actinomycin D.

Apoptotic cells were also visualized by fluorescence microscopy. ${ }^{41}$ Cell suspension was mixed with an equal volume of a solution containing $0.01 \%$ ethidium bromide and $0.003 \%$ acridine orange. A Nikon Eclipse E400 microscope (Nikon, Tokyo, Japan) was used for visualization. Apoptosis was quantitatively analyzed by flow cytometry using double staining with annexin V-FITC/propidium iodide (PI). Briefly, cells were washed twice with PBS, and then incubated for $20 \mathrm{~min}$ with annexin $\mathrm{V}$ at $4{ }^{\circ} \mathrm{C}$ in the dark. Early (annexin $\mathrm{V}^{+} / \mathrm{PI}^{-}$) and late (annexin $\mathrm{V}^{+} / \mathrm{PI}^{+}$) apoptotic events were quantified. Fluorescence was detected using a FACSCalibur cytometer (BD Pharmigen).

TUNEL assay (Promega) was also used to study late apoptosis by flow cytometry according to manufacturer's instructions. Briefly, cells were washed, fixed with $4 \%$ paraformaldehyde in PBS, permeabilized with ethanol, and then incubated with TdT enzyme plus deoxinucleotides and fluorescein-12-dUTP for $1 \mathrm{~h}$ at $37^{\circ} \mathrm{C}$. Cells were washed, stained with $\mathrm{PI}$ and analyzed by flow cytometry (FACSCalibur cytometer). Fluorescein-12-dUTP incorporation results in green fluorescence within the nucleus of apoptotic cells; PI stains both apoptotic and non-apoptotic cells.

Fluorometric analysis of caspase-3 activity. Cells were lysed in ice-cold lysate buffer (10 mM EDTA, $50 \mathrm{mM}$ Tris- $\mathrm{HCl}(\mathrm{pH} 7.4), 150 \mathrm{mM}$ sodium chloride, $1 \%$ Triton X100, $2 \mathrm{mM}$ phenylmethylsulfonyl fluoride, $2 \mathrm{mM}$ sodium orthovanadate, $10 \mathrm{mg} / \mathrm{ml}$ leupeptin and $2 \mathrm{mg} / \mathrm{ml}$ aprotinin) and the protein content was quantified with the bicinchoninic acid kit (Pierce BCA Protein Assay, Pierce, Rockford, IL, USA), using BSA as standard. Lysates were incubated with the caspase-3-specific substrate Ac-DEVD-AFC (Biomol International, Plymouth Meeting, PA, USA). Briefly, the fluorogenic AFC is released from the substrate by the caspase- 3 action and it is spectrofluorometrically detected at $505 \mathrm{~nm}$ after excitation $(400 \mathrm{~nm})$. The arbitrary fluorescence units were normalized to the total protein content of the sample. In order to evaluate the specificity of the reaction, a control including the caspase-3 specific inhibitor Ac-DEVD-CHO ( $\mathrm{N}$-acetyl-Asp-Glu-Val-Asp-CHO aldehyde) (Biomol International) was performed. 
Analysis of the mitochondrial pathway by flow cytometry. The Mitochondrial Permeability Detection Kit (MTt-E- $\varphi$, Biomol International) was used to analyze the mitochondrial membrane potential according to manufacturer's instructions. Briefly, 5,5',6,6'-tetrachloro-1,1',3,3'-tetraethyl-benzamidazolocarbocyanin iodide (JC-1) accumulates in healthy mitochondria giving rise to a red fluorescent signal. When the mitochondrial membrane potential declines as a consequence of the induction of apoptosis, a green fluorescence can be detected in mitochondria due to dye distribution within the cell. ${ }^{42,19}$ Cells were incubated with the MTt-E- $\varphi$ reagent for $15 \mathrm{~min}$ at $37^{\circ} \mathrm{C}$, and after washing they were resuspended in PBS. Fluorescence was detected by flow cytometry.

In vivo assessment of Gal-1-induced apoptosis in epithelial cells. Young male mice ( $N=5$ per group), $25-30 \mathrm{~g}$ of weight, were fasted overnight and anaesthetized by intraperitoneal injection of ketamine $(100 \mathrm{mg} / \mathrm{kg})$ and xylacine $(5 \mathrm{mg} / \mathrm{kg})$. The ligated intestinal loop technique was performed as follows: a small longitudinal incision was practiced in the lower abdomen and a $2 \mathrm{~cm}$ section of small intestine from duodenum was clamped. Next, $100 \mu \mathrm{l}$ of saline solution (control) or saline plus rGal-1 $(20 \mu \mathrm{M})$ or BSA $(20 \mu \mathrm{M})$ were injected in independent loops in the same animal. The abdominal wall was then sutured. During the procedure mice were kept warm on a $37^{\circ} \mathrm{C}$ warming pad and anesthetized. Three hours later animals were killed by cervical dislocation and the different loops were individually processed. Apoptosis was evaluated by flow cytometry using annexin V/ PI staining and by TUNEL assay in paraffin-embedded tissue sections as previously described.

Proliferation assay. Proliferation was determined using bromodeoxyuridine (BrdU) In-Situ Detection Kit (BD Pharmingen) according to manufacturer's instructions. Briefly, wild-type and $L$ gals ${ }^{-1-}$ mice were given an intraperitoneal injection of $1 \mathrm{mg} / \mathrm{ml}$ $\mathrm{BrdU}$ in phosphate buffer ( $\mathrm{pH}$ 7.4). Mice were killed $24 \mathrm{~h}$ later by cervical dislocation; enterocytes were isolated and further permeabilized. Cells were cultured with anti-BrdU labeled with FITC and fluorescence was analyzed by flow cytometry.

Starvation experiment. Adult wild-type $(n=14)$ and $L$ gals $1^{-1-}(n=14)$ mice (weight $25-30 \mathrm{~g}$ ) were used. All animals received water ad libitum. For each group seven animals were fed mouse chow ad libitum (control groups) whereas the remaining seven mice were starved for $48 \mathrm{~h}$. Finally, all animals were killed and the small bowel was analyzed.

Statistical analysis. Comparison of two groups (means) was performed by using the one-way ANOVA and Student's $t$ test for the comparison of paired samples. Results represent the mean \pm S.E.M. All results with $P<0.05$ were considered statistically significant.

\section{Conflict of Interest}

The authors declare no conflict of interest.

Acknowledgements. We thank F Poirier (Institute Jacques Monod) for providing $L g a l s 1^{-1-}$ mice. We also thank Liliana Bruzzone for assistance with spectrofluorometric determinations, Carolina Zanuzzi for the histological sample preparation and Pablo Stringa for ligated loop assays. This work was supported by grants PICT 25417 (GHD) and PICT 2006-603 (GAR) from the Argentinean Agency for Promotion of Science and Technology, PIP 0938 (CM) from the Argentinean National Research Council (CONICET), University of Buenos Aires (GAR) and Fundación Sales (GAR).

1. Mowat AM. Anatomical basis of tolerance and immunity to intestinal antigens. Nat Rev Immunol 2003; 3: 331-341.

2. Gordon Jl, Hermiston ML. Differentiation and self-renewal in the mouse gastrointestinal epithelium. Curr Opin Cell Biol 1994; 6: 795-803.

3. Gassler N, Roth W, Funke B, Schneider A, Herzog F, Tischendorf JJ et al. Regulation of enterocyte apoptosis by acyl-CoA synthetase 5 splicing. Gastroenterology 2007; 133: 587-598.

4. Rabinovich GA, llarregui JM. Conveying glycan information into T-cell homeostatic programs: a challenging role for galectin-1 in inflammatory and tumor microenvironments. Immunol Rev 2009; 230: 144-159.

5. Toscano MA, Bianco GA, llarregui JM, Croci DO, Correale J, Hernandez JD et al. Differential glycosylation of $\mathrm{TH} 1, \mathrm{TH} 2$ and $\mathrm{TH}-17$ effector cells selectively regulates susceptibility to cell death. Nat Immunol 2007; 8: 825-834.

6. Ilarregui JM, Croci DO, Bianco GA, Toscano MA, Salatino M, Vermeulen ME et al. Tolerogenic signals delivered by dendritic cells to $T$ cells through a galectin-1-driven immunoregulatory circuit involving interleukin 27 and interleukin 10. Nat Immunol 2009: 10 : 981-991.

7. Santucci L, Fiorucci S, Rubinstein N, Mencarelli A, Palazzetti B, Federici B et al. Galectin-1 suppresses experimental colitis in mice. Gastroenterology 2003; 124: 1381-1394.

8. Toscano MA, Commodaro AG, llarregui JM, Bianco GA, Liberman A, Serra HM et al. Galectin-1 suppresses autoimmune retinal disease by promoting concomitant Th2- and T regulatory-mediated anti-inflammatory responses. J Immunol 2006; 176: 6323-6332.

9. Norling LV, Sampaio ALF, Cooper D, Perretti M. Inhibitory control of endothelial galectin-1 on in vitro and in vivo lymphocyte trafficking. FASEB J 2008; 22: 682-690.

10. Salatino M, Rabinovich GA. Fine-tuning antitumor responses through the control of galectin-glycan interactions: an overview. Methods Mol Biol 2011; 677: 355-374.

11. Kovács-Sólyom F, Blaskó A, Fajka-Boja R, Katona RL, Végh L, Novák J et al. Mechanism of tumor cell-induced T-cell apoptosis mediated by galectin-1. Immunol Lett 2010; 127: 108-118

12. Hittelet $A$, Legendre $H$, Nagy $N$, Bronckart $Y$, Pector JC, Salmon I et al. Upregulation of galectins- 1 and -3 in human colon cancer and their role in regulating cell migration. Int J Cancer 2003; 103: 370-379.

13. Mercer N, Guzman L, Cueto Rua E, Drut R, Ahmed H, Vasta GR et al. Duodenal intraepithelial lymphocytes of children with cow milk allergy preferentially bind the glycanbinding protein galectin-3. Int J Immunopathol Pharmacol 2009; 22: 207-217.

14. Mathieu A, Nagy N, Decaestecker C, Ferdinande L, Vandenbroucke K, Rottiers $P$ et al. Expression of galectins $-1,-3$ and -4 varies with strain and type of experimental colitis in mice. Int J Exp Pathol 2008; 89: 438-446.

15. Demetter $P$, Nagy N, Martin B, Mathieu A, Dumont $P$, Decaestecker $C$ et al. The galectin family and digestive disease. J Pathol 2008; 215: 1-12.

16. Sanjuán X, Fernández PL, Castells A, Castronovo V, van den Brule F, Liu FT et al. Differential expression of galectin 3 and galectin 1 in colorectal cancer progression. Gastroenterology 1997; 113: 1906-1915.

17. Paclik D, Berndt U, Guzy C, Dankof A, Danese S, Holzloehner P et al. Galectin-2 induces apoptosis of lamina propria $T$ lymphocytes and ameliorates acute and chronic experimental colitis in mice. J Mol Med 2008; 86: 1395-1406.

18. Perillo NL, Pace KE, Seilhamer JJ, Baum LG. Apoptosis of T cells mediated by galectin-1. Nature 1995; 378: 736-73 739

19. Matarrese P, Tinari A, Mormone E, Bianco GA, Toscano MA, Ascione B et al. Galectin-1 sensitizes resting human $T$ lymphocytes to Fas (CD95)-mediated cell death via mitochondrial hyperpolarization, budding, and fission. J Biol Chem 2005; 280: 6969-6985.

20. Leedham SJ, Brittan M, McDonald SAC, Wright NA. Intestinal stem cells. J Cell Mol Med 2005; 9: 11-24.

21. Chappell VL, Thompson MD, Jeschke MG, Chung DH, Thompson JC, Wolf SE. Effects of incremental starvation on gut mucosa. Dig Dis Sci 2003; 48: 765-769.

22. Jass JR, Walsh MD. Altered mucin expression in the gastrointestinal tract: a review. J Cell Mol Med; 2001; 5: 327-351.

23. Paschos KA, Canovas D, Bird NC. The engagement of selectins and their ligands in colorectal cancer liver metastases. J Cell Mol Med 2010; 14: 165-174.

24. Poirier F, Bourin P, Bladier D, Joubert-Caron R, Caron M. Effect of 5-azacytidine and galectin-1 on growth and differentiation of the human $b$ lymphoma cell line bl36. Cance Cell Int 2001; $1: 2$.

25. Martinez VG, Pellizzari EH, Díaz ES, Cigorraga SB, Lustig L, Denduchis B et al. Galectin-1, a cell adhesion modulator, induces apoptosis of rat Leydig cells in vitro. Glycobiology 2004; 14: $127-137$

26. Ellerhorst J, Nguyen T, Cooper DN, Estrov Y, Lotan D, Lotan R. Induction of differentiation and apoptosis in the prostate cancer cell line LNCaP by sodium butyrate and galectin-1. Int J Oncol 1999; 14: 225-232.

27. Wiest I, Seliger C, Walzel H, Friese K, Jeschke U. Induction of apoptosis in human breast cancer and trophoblast tumor cells by galectin-1. Anticancer Res 2005; 25: 1575-1580.

28. Paclik D, Lohse K, Wiedenmann B, Dignass AU, Sturm A. Galectin-2 and -4 , but not galectin-1, promote intestinal epithelial wound healing in vitro through a TGF-betaindependent mechanism. Inflamm Bowel Dis 2008; 14: 1366-1372.

29. Wells V, Davies D, Mallucci L. Cell cycle arrest and induction of apoptosis by beta galactoside binding protein (beta GBP) in human mammary cancer cells. A potential new approach to cancer control. Eur J Cancer 1999; 35: 978-983.

30. Lièvre A, Samalin E, Mitry E, Assenat E, Boyer-Gestin C, Lepère $C$ et al. Bevacizumab plus FOLFIRI or FOLFOX in chemotherapy-refractory patients with metastatic colorectal cancer: a retrospective study. BMC Cancer 2009; 9: 347.

31. Rabinovich GA, Toscano MA. Turning 'sweet' on immunity: galectin-glycan interactions in immune tolerance and inflammation. Nat Rev Immunol 2009: 9: 338-352.

32. Di Sabatino A, Ciccocioppo R, Cinque B, Millimaggi D, Morera R, Ricevuti L et al. Defective mucosal $\mathrm{T}$ cell death is sustainably reverted by infliximab in a caspase dependent pathway in Crohn's disease. Gut 2004; 53: 70-77.

33. Souza HS, Tortori CJ, Castelo-Branco MT, Carvalho AT, Margallo VS, Delgado CF et al. Apoptosis in the intestinal mucosa of patients with inflammatory bowel disease: evidence of altered expression of FasL and perforin cytotoxic pathways. Int J Colorectal Dis 2005; 20: 277-286

34. Nio J, Kon Y, Iwanaga T. Differential cellular expression of galectin family mRNAs in the epithelial cells of the mouse digestive tract. J Histochem Cytochem 2005; 53: 1323-1334.

35. Nio-Kobayashi J, Takahashi-Iwanaga $\mathrm{H}$, Iwanaga $\mathrm{T}$ Immunohistochemical localization of six galectin subtypes in the mouse digestive tract. J Histochem Cytochem 2009; 57: 41-50. 
36. Ciccocioppo R, Di Sabatino A, Parroni R, Muzi P, D’Alò S, Ventura T et al. Increased enterocyte apoptosis and Fas-Fas ligand system in celiac disease. Am J Clin Pathol 2001; 115: 494-503.

37. Heller F, Florian P, Bojarski C, Richter J, Christ M, Hillenbrand B et al. 2005 Interleukin-13 is the key effector Th2 cytokine in ulcerative colitis that affects epithelial tight junctions, apoptosis, and cell restitution. Gastroenterology 2005; 129: 550-564.

38. Docena G, Rovedatti L, Kruidenier L, Fanning A, Leakey NA, Knowles CH et al. Downregulation of p38 mitogen-activated protein kinase activation and proinflammatory cytokine production by mitogen-activated protein kinase inhibitors in inflammatory bowel disease. Clin Exp Immunol 2010; 162: 108-115.

39. Rumbo M, Sierro F, Debard N, Kraehenbuhl JP, Finke D. Lymphotoxin beta receptor signaling induces the chemokine CCL20 in intestinal epithelium. Gastroenterology 2004; 127: 213-223.

40. Leonardi E, Girlando S, Serio G, Mauri FA, Perrone G, Scampini S et al. PCNA and Ki67 expression in breast carcinoma: correlations with clinical and biological variables. J Clin Pathol 1992; 45: 416-419.
41. Parks DR, Bryan VM, Oi VT, Herzenberg LA. Antigen-specific identification and cloning of hybridomas with a fluorescence-activated cell sorter. Proc Natl Acad Sci USA 1979; 76 1962-1966.

42. Cossarizza A, Baccarani-Contri M, Kalashnikova G, Franceschi C. A new method for the cytofluorimetric analysis of mitochondrial membrane potential using the $\mathrm{J}$-aggregate forming lipophilic cation 5,5',6,6'-tetrachloro-1,1',3,3'-tetraethylbenzimidazolcarbocyanine iodide (JC-1). Biochem Biophys Res Commun 1993; 197: 40-45.

Cell Death and Disease is an open-access journal published by Nature Publishing Group. This work is licensed under the Creative Commons Attribution-Noncommercial-Share Alike 3.0 Unported License. To view a copy of this license, visit http:// creativecommons.org/licenses/by-nc-sa/3.0/ 